\title{
Preparation, Characterization and Catalytic Activity of Tin Dioxide and Zero-Valent Tin Nanoparticles
}

\author{
H. R. Pouretedal ${ }^{*}$, A. Shafeie ${ }^{\dagger}$, and M. H. Keshavarz \\ Faculty of Applied Chemistry, Malek-ashtar University of Technology, Shahin-Shahr, Iran. \\ "E-mail: HR_POURETEDAL@mut-es.ac.ir \\ 'Department of Chemistry, Islamic Azad University, Shahreza Branch, Shahreza, Iran
}

(Received January 18, 2012; Accepted June 4, 2012)

\begin{abstract}
The tin (IV) oxide nanoparticles are prepared by controlled precipitation method and calcined at temperatures of $200-600{ }^{\circ} \mathrm{C}$. The prepared $\mathrm{SnO}_{2}$ nanoparticles characterized by XRD patterns, TEM image, IR and UV-Vis spectra. The XRD patterns and TEM image show the tetragonal structure and spherical morphology for $\mathrm{SnO}_{2}$ nanoparticles, respectively. The photocatalytic activity of the prepared $\mathrm{SnO}_{2}$ nanoparticles studied in degradation reaction of methylene blue (MB). The results show the size of nanoparticles, band-gap energy and photocatalytic activity of $\mathrm{SnO}_{2}$ depends on the calcinations temperature. The $\mathrm{SnO}_{2}$ nanoparticles calcined at $500{ }^{\circ} \mathrm{C}$ indicated the highest photoreactivity. Also, the zero-valent tin (ZVT) nanoparticles with tetragonal structure are prepared by a reducing agent and used as a catalyst in degradation of MB. In basic $\mathrm{pH}$ of 11 , the degradation $>95 \%$ of $\mathrm{MB}$ at time $150 \mathrm{~min}$ obtained at presence of ZVT nanoparticles.
\end{abstract}

Key words: $\mathrm{SnO}_{2}$, Sn, Nanoparticles, Methylene blue, Photocatalyst

\section{INTRODUCTION}

Nanometer range semiconducting materials have been a subject of intense study for last several years due to their size dependent physical and chemical properties below a critical size characteristic of the material. ${ }^{1,2}$ Photocatalytic property is a interesting property that exhibited by these nanocrystals. This property is size quantization effect which arise due to the increasing quantum confinement of the electrons and holes with diminishing size of the crystallites and the consequent changes in the electronic structures. ${ }^{3-5}$

The performance and application of semiconductor photocatalyst are largely based on how much its electronic structure and photoinduced charge property at the surface or interface are realized. ${ }^{5}$ The studies on the effects of some factors, such as material size, phase composition, structure and dopant species, on the properties of photoinduced charges, including charge transfer behavior and surface states, are of very significance to the preparation and application of semiconductor materials. ${ }^{4}$

Semiconductor photocatalysis has attracted increasing attention as an effective technique to eliminate the pollutants in air and wastewater. While many efforts have been made to put this technique into commercial application, many problems arise, such as the fast recombination rate of the photoexcited electron-hole pairs, which is the key factor in the process of semiconductor photocatalysis. ${ }^{6,7}$ Therefore, there has been much interest in lowering the recombination rate of electron-hole pairs in order to improve the photocatalytic efficiency of semiconductor photocatalysts. ${ }^{8}$

Tin (IV) oxide has been a widely studied material over decades because of its wide range of applications as gas sensors, heat mirrors, and transparent electrodes for solar cells, opto-electronic devices and in catalysis. ${ }^{9}$ Tin dioxide is an $n$-type semiconductor crystallizing in tetragonal rutile structure and having the band-gap of about $3.65 \mathrm{eV}$ at bulk state. ${ }^{10}$

Applications of Sn (0) nanoparticles are in the preparation of metal films, as Li alloy anodes for rechargeable batteries, as precursors to $\mathrm{SnO}_{2}$ nanoparticles for use as gas sensors and in heterogeneous catalysis. ${ }^{11,12}$ However, despite the unique properties of $\mathrm{Sn}(0)$ particles in hybrid materials or catalysis, there are only a few reports dealing with their preparation. Evaporation under ultrahigh vacuum of bulk tin followed by condensation of the vapor is by far the most common method for the synthesis of $\mathrm{Sn}(0)$ particles. $^{13,14}$

In this work, the production of $\mathrm{SnO}_{2}$ and zero-valent tin (ZVT) nanoparticles and characterization of prepared nanoparticles is reported. The effect of calcinations temperature studied on the photocatalytic activity of $\mathrm{SnO}_{2}$ nanoparticles. The bleaching of methylene blue is also 
studied in presence of $\mathrm{SnO}_{2}$ and zero-valent tin (ZVT) nanoparticles.

\section{EXPERIMENTAL}

\section{Synthesis of $\mathrm{SnO}_{2}$ and $\mathrm{Sn}$ Nanoparticles}

All materials were purchased from Merck and Aldrich Company with high purity and analytical grade. The double distilled water was used to prepare the aqueous solutions.

Tin (IV) chloride ( $\left.\mathrm{SnCl}_{4} \cdot 5 \mathrm{H}_{2} \mathrm{O}\right)$ and ammonia solution (1:1) with high purity and analytical grade were used as precursor for synthesis of $\mathrm{SnO}_{2}$ nanoparticles. A controlled precipitation procedure used to prepare the $\mathrm{SnO}_{2}$ nanoparticles. Firstly, ammonia solution was added to $50 \mathrm{ml}$ of $0.05 \mathrm{M} \mathrm{SnCl}_{4}$ solution drop by drop using a decanter with control of sample $\mathrm{pH}$ while the mixture was stirred vigorously at $80{ }^{\circ} \mathrm{C}$ temperature. The $\mathrm{pH}$ of sample was controlled at $\mathrm{pH}$ of 3-4 and heating and stirring of sample was continued duration 2-3 $\mathrm{h}$. The white precipitate of $\mathrm{Sn}(\mathrm{OH})_{4}$ was then centrifuged at 3000-4000 rpm, washed with water and ethanol several times. The $\mathrm{Sn}(\mathrm{OH})_{4}$ nanoparticles were treated by heating in temperature of $80^{\circ} \mathrm{C}$ for about $4 \mathrm{~h}$. Finally, the white $\mathrm{SnO}_{2}$ powders were calcined in an oven at temperatures of $200-600{ }^{\circ} \mathrm{C}$ for about $2 \mathrm{~h}$ and then stored for further use.

The zero-valent tin nanoparticles were prepared by $\mathrm{SnCl}_{2}$ as starting material, sodium borohydride $\left(\mathrm{NaBH}_{4}\right)$ as reducing agent and Tween 80 as surfactant. Sodium borohydride solution $(0.06 \mathrm{M})$ was added to a solution of $0.1 \% \mathrm{w} / \mathrm{w} \mathrm{SnCl}_{2}$ and $0.2 \% \mathrm{w} / \mathrm{w}$ of Tween 80 so that one drop was added each of 3-4 s. The Sn nanoparticles was removed by centrifuge with $3000-4000 \mathrm{rpm}$ and then washed with water and ethanol several times and dried at $50-60{ }^{\circ} \mathrm{C}$ at time $2-3 \mathrm{~h}$.

\section{Characterization of Nanoparticles}

The prepared nanoparticles characterized by using Xray diffraction (XRD) patterns, IR spectra, UV-Vis spectra and TEM images. An X-ray Diffractometer Bruker D8ADVANCE Germany with anode of $\mathrm{Cu}$ (wavelength of $1.5406 \AA$ of $\left(\mathrm{Cu} \mathrm{K}_{\alpha}\right.$ ) and filter of $\mathrm{Ni}$ apply to record the XRD patterns of nanosized powders. The nanoparticles size was estimated by a JEOL JEM-1200EXII transmission electron microscope (TEM) operating at $120 \mathrm{kV}$. The supporting grids were formvar-covered, carbon-coated, 200-mesh copper grids. IR-spectra of $\mathrm{SnO}_{2}$ nanoparticles in range $4000-400 \mathrm{~cm}^{-1}$ were recorded by using Nicolet Impact 400D FT-IR Spectrophotometer. UV-Vis Spectro- photometer Carry-100 used to record absorption spectra of synthesized $\mathrm{SnO}_{2}$ in range of 200-500 nm. B.E.T (Brunauer-Emmett-Teller) surface area of nanoparticles was determined by using Monosorb Quantochorom.

\section{Catalytic Activity of Nanoparticles}

The photocatalytic activity of $\mathrm{SnO}_{2}$ nanoparticles studied in the degradation reaction of methylene blue (MB). A photocatalytic reactor system with a mercury low pressure lamp $(70 \mathrm{~W})$ with $\lambda_{\max }=332 \mathrm{~nm}$ and light intensity 22 $\mathrm{W} / \mathrm{m}^{2}$ used to measure photoactivity of $\mathrm{SnO}_{2}$ nanoparticles. The lamp and the tube were then immersed in the photoreactor cell with a light path of $3.0 \mathrm{~cm}$. The photoreactor was filled with $50 \mathrm{ml}$ sample contain 10.0-50.0 $\mathrm{mg} / \mathrm{L} \mathrm{MB}$ and 0.0-1.2 g/L nanoparticles of $\mathrm{SnO}_{2}$. The temperature of photoreactor was kept at $25^{\circ} \mathrm{C}$ with a watercooled jacket on its outside. A magnetic stirrer applied to ensure that the suspension of the heterogeneous catalyst is uniform during the degradation. Batch experiments were also performed to study the effect of ZVT nanoparticles in degradation of MB. Dye solution $(10-50 \mathrm{mg} / \mathrm{L})$ was prepared in deionized water. A $100 \mathrm{~mL}$ of MB solution was poured into a $250-\mathrm{mL}$ Erlenmeyer flask and $0.8 \mathrm{~g} / \mathrm{L}$ of ZVT nanoparticles was added.

The degraded samples collected at regular intervals, filtered through Millipore membrane filters, and centrifuged to remove the particles. The collected samples were analyzed to measure the absorbance of dye by using a UV-Vis spectrophotometer. The decrease of absorbance value of samples at $\lambda_{\max }$ of dye $(625 \mathrm{~nm})$ in certain time intervals shows the rate of degradation efficiency $(\% \mathrm{D})$ and calculated by Eq (1):

$$
\% \mathrm{D}=100 \times\left[\left(\mathrm{C}_{0}-\mathrm{C}_{\mathrm{t}}\right) / \mathrm{C}_{\mathrm{o}}\right]=100 \times\left[\left(\mathrm{A}_{0}-\mathrm{A}_{\mathrm{t}}\right) / \mathrm{A}_{\mathrm{o}}\right]
$$

In $\mathrm{Eq}(1), \mathrm{C}_{\mathrm{o}}$ and $\mathrm{C}_{\mathrm{t}}$ are the initial concentration and concentration of dye at time $t$, respectively, and $A_{o}$ and $A_{t}$ are the initial absorbance and absorbance of dye at time $t$, respectively.

\section{Kinetic Study of Catalyzed Degradation}

The simplified pseudo-first order kinetic model of Langmuir-Hinshelwood (Eq. 2) use to calculate the apparent rate constant of degradation process of dye at initial concentrations 10, 20, 30, 40 and $50 \mathrm{mg} / \mathrm{L}$ at $\mathrm{pH} 11$.

$\ln \left(C_{o} / C_{t}\right)=k K t=K_{\text {app }} t$

In Eq. (2), $C$ is concentration of the dye $(\mathrm{mg} / \mathrm{L}), t$ is degradation time ( $\mathrm{min}), k$ is reaction rate constant $\left(\mathrm{min}^{-1}\right), K$ is the adsorption coefficient of the dye onto the catalyst par- 
ticles $(\mathrm{L} / \mathrm{mg})$ and $k_{\text {app }}$ is the apparent rate constant $\left(\mathrm{min}^{-1}\right)$.

The photocatalytic activity of prepared $\mathrm{SnO}_{2}$ was also studied under sunlight irradiation and also compared to commercial $\mathrm{SnO}_{2}$. The recovery of catalysts and reusability of them were studied at optimum conditions. Also, the MB bleaching catalyzed by nanosized $\mathrm{SnO}_{2}$ was studied in presence of chloride, bromide, iodide, carbonate, sulfate, phosphate, nitrate anions and magnesium and calcium cations as like a real sample.

\section{RESULTS AND DISCUSSION}

\section{Characterization of $\mathrm{SnO}_{2}$ and Zero-valent Tin Nano- particles}

Figs. 1A-1D show the XRD patterns of $\mathrm{SnO}_{2}$ nanoparticles that are calcined at temperatures of $300,400,500$ and $600{ }^{\circ} \mathrm{C}$ in time $2 \mathrm{~h}$, respectively. As seen, in all temperatures, the calcined $\mathrm{SnO}_{2}$ particles show the diffraction peaks of (110), (101), (200), (111), (211), (220), (002), (311), (112), (301), (202) and (321) at 2q of 26.8, $33.9,37.9,39.0,51.8,54.8,57.7,61.8,64.8,66.0,71.2$ and $78.6^{\circ}$, respectively. Which matches well with JCPDS card \# 41-1445 and structure of the crystal is found to be Cassiterite type tetragonal of $\mathrm{SnO}_{2}$ crystal. ${ }^{10,11,15}$ But, the crystalinity of particles as well as the particles size increase with increasing of calcinations temperature. The XRD patterns show the decreasing of FWHM and thus increasing of particles size of $\mathrm{SnO}_{2}$ with increasing of calcinations temperature from 300 to $600{ }^{\circ} \mathrm{C}$. The average crystallite size of the tin dioxide crystal calcined at 300, 400, 500 and

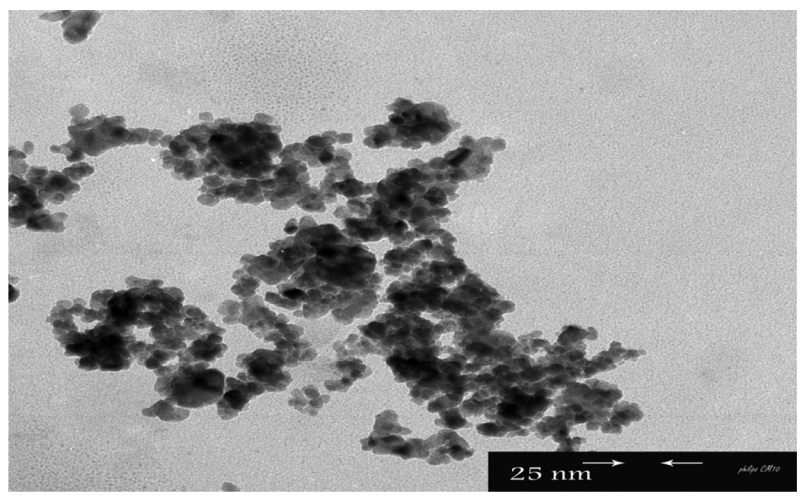

Fig. 2. TEM image of $\mathrm{SnO}_{2}$ nanoparticles calcined at $500{ }^{\circ} \mathrm{C}$.

$600{ }^{\circ} \mathrm{C}$ was calculated from Debye-Scherrer formula $\mathrm{a}^{15}$ and found $2.46,3.48,5.21$ and $8.31 \mathrm{~nm}$, respectively. The TEM micrograph of $\mathrm{SnO}_{2}$ nanoparticles calcined at 500 ${ }^{\circ} \mathrm{C}$ is shown in Fig. 2 that reveals the morphology and particles size. The monodispersed particles with spherical shape and size $<25 \mathrm{~nm}$ with an equable distribution except for a little aggregated particulate, is observed in TEM image. On the other hand, the TEM photographs show that tin (IV) oxide powder is nanometer scale, which is in reasonable agreement with the results obtained from the XRD patterns.

The FT-IR spectra of $\mathrm{SnO}_{2}$ nanoparticles (Fig. 3) show the bands of $600-700 \mathrm{~cm}^{-1}$ that are assigned to the antisymmetric Sn-O-Sn stretching mode of the surface-bridging of oxide. ${ }^{16}$ The UV-Vis spectra of $\mathrm{SnO}_{2}$ calcined at temperatures of 400, 500 and $600{ }^{\circ} \mathrm{C}$ are shown in Fig. 4.
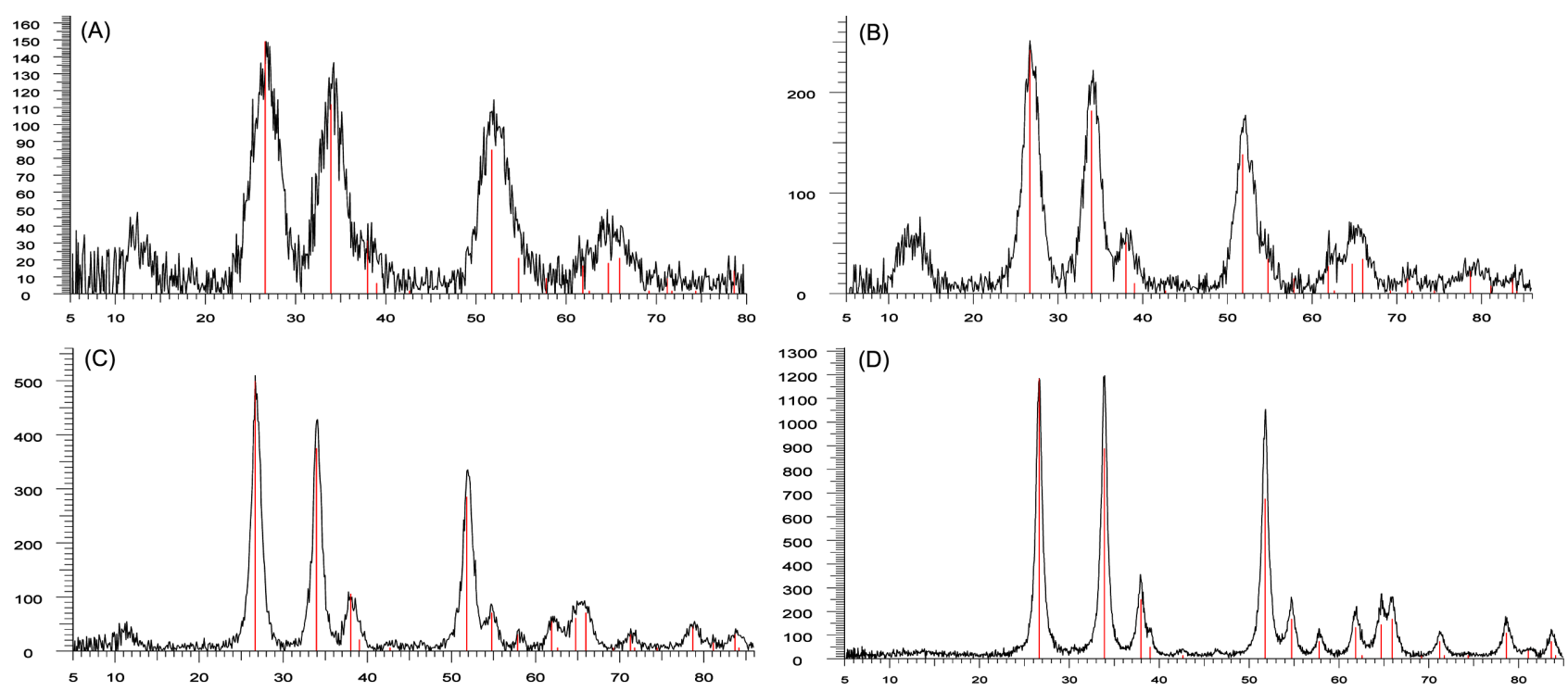

Fig. 1. (A) XRD pattern of $\mathrm{SnO}_{2}$ nanoparticles calcined at $300{ }^{\circ} \mathrm{C}$, (B) XRD pattern of $\mathrm{SnO}_{2}$ nanoparticles calcined at $400{ }^{\circ} \mathrm{C}$, (C) $\mathrm{XRD}$ pattern of $\mathrm{SnO}_{2}$ nanoparticles calcined at $500{ }^{\circ} \mathrm{C}$. (D) $\mathrm{XRD}$ pattern of $\mathrm{SnO}_{2}$ nanoparticles calcined at $600{ }^{\circ} \mathrm{C}$. 


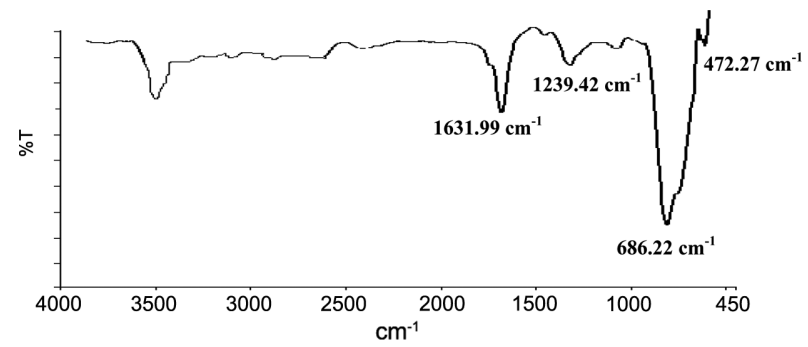

Fig. 3. FT-IR spectra of $\mathrm{SnO}_{2}$ calcined at $500{ }^{\circ} \mathrm{C}$.

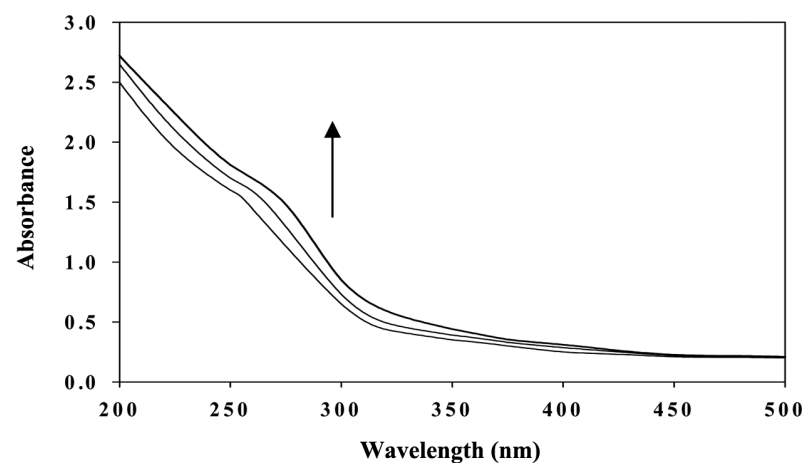

Fig. 4. The UV-Vis spectra of $\mathrm{SnO}_{2}$ nanoparticles calcined at 400,500 and $600{ }^{\circ} \mathrm{C}$ from down to up.

The red-shift in absorption edge is observed with increasing of temperature. So that, the wavelength of absorption edge is observed at 262,268 and $275 \mathrm{~nm}$ for $\mathrm{SnO}_{2}$ calcined at temperatures of 400,500 and $600{ }^{\circ} \mathrm{C}$, respectively. ${ }^{17,18}$

Figs. 5 and 6 indicate the XRD pattern and TEM micrograph of zero-valent Sn nanoparticles, respectively. The XRD pattern show diffraction peaks that are indexed to a tetragonal cell for tin particles (JCPDS \#04-0673). ${ }^{19,20}$ The crystallite size of tin nanoparticles with Scherrer formula is estimated to be $16.62 \mathrm{~nm}$. The TEM micrograph is also confirmed the formation of tin nanoparticles with size less of $20 \mathrm{~nm}$ by reduction of $\mathrm{Sn}^{2+}$ ions by $\mathrm{NaBH}_{4}$ at presence of Tween 80 . Also, the B.E.T analysis indicated that the surface area of zero-valent tin nanoparticles is $15.8 \mathrm{~m}^{2} / \mathrm{g}$.

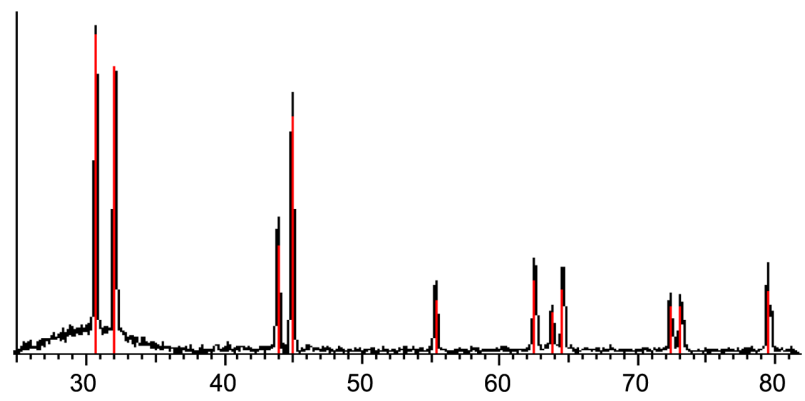

Fig. 5. XRD pattern of zero-valent tin nanoparticles.

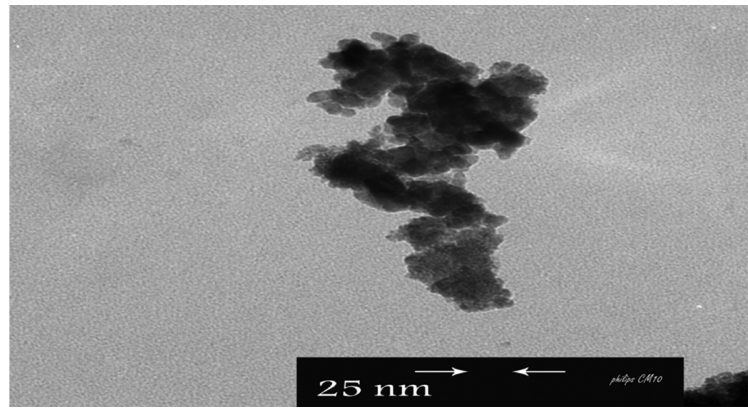

Fig. 6. TEM image of zero-valent tin nanoparticles.

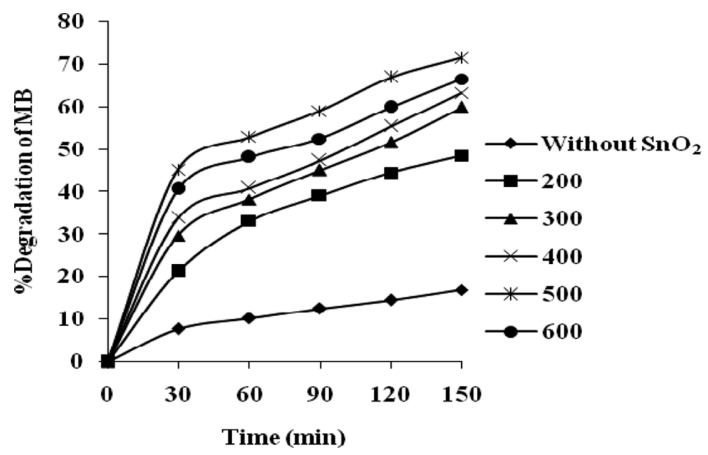

Fig. 7. Effect of calcination temperature $\left({ }^{\circ} \mathrm{C}\right)$ on the photocatalytic activity of $\mathrm{SnO}_{2}$ nanoparticles.

\section{Photocatalytic Activity of $\mathrm{SnO}_{2}$ Nanoparticles}

The photocatalytic activity of $\mathrm{SnO}_{2}$ can be dependent on the preparation conditions such as time and temperature of treatment and calcination process. The effect of calcination temperature on the photocatalytic activity of $\mathrm{SnO}_{2}$ in methylene blue degradation is shwon in Fig. 7. The conditions are $0.1 \mathrm{~g} / \mathrm{L}$ catalyst, $\mathrm{pH}$ of 7 and $\mathrm{MB}$ of 10 $\mathrm{mg} / \mathrm{L}$. As seen, the highest photocatalytic activity is due to $\mathrm{SnO}_{2}$ nanoparticles calcined at $500{ }^{\circ} \mathrm{C}$. As mentioned (Figs. 1A to 1D), the crystallinity and powder size of $\mathrm{SnO}_{2}$ nanoparticles increase with increasing of calcinations temperature. On the other hand, the band-gap energy is calculated 4.72, 4.62 and $4.50 \mathrm{eV}$ for $\mathrm{SnO}_{2}$ nanoparticles calcined at temperatures of 400,500 and $600{ }^{\circ} \mathrm{C}$, respectively (Fig. 4). The band-gap energy of semiconductors is related to their photocatalytic activity for phtodegradation of pollutants. The greater of redox potential of the photogenerated electron-hole pairs is due to the larger of band-gap energy. Thus, a semiconductor exhibits more redox capacity with increase of band-gap. ${ }^{21,22}$ Therefore, the most degradation for MB is seen in presence of $\mathrm{SnO}_{2}$ calcined at $500{ }^{\circ} \mathrm{C}$ with band-gap energy of $4.62 \mathrm{eV}$ and size of $5.21 \mathrm{~nm}$. The $\mathrm{SnO}_{2}$ calcined at $600{ }^{\circ} \mathrm{C}$ show the lower activity despite of having the lower bandgap energy. This decrease is related to increasing of par- 


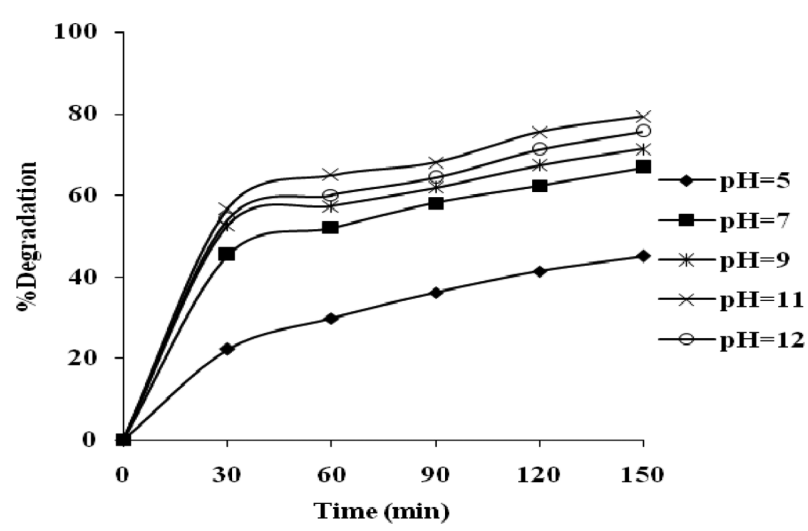

Fig. 8. Effect of samples $\mathrm{pH}$ on the photocatalytic activity of $\mathrm{SnO}_{2}$ nanoparticles.

ticles size and thus the decrease of surface due to agglomeration of them in $600{ }^{\circ} \mathrm{C}$ temperature.

The photocatalytic activity of a semiconductor is related to the $\mathrm{pH}$ of samples and dosage of it. The effects of $\mathrm{pH}$ and amount of $\mathrm{SnO}_{2}$ nanoparticles are indicated in Figs. 8 and 9, respectively. The Fig. 8 shows the increasing of photocatalytic activity of $\mathrm{SnO}_{2}$ nanoparticels with increasing of samples $\mathrm{pH}$. The increasing of $\mathrm{pH}$ is due to increase hydroxyl ions concentration to react with the holes and formation hydroxyl radicals. Also, the adsorption of MB molecules with positive charge is occurred on the surface of catalyst in basic solutions because the negative charge of $\mathrm{SnO}_{2}$ with $\mathrm{pH}$ of isoelectric point of 3.5. ${ }^{22}$ However, the degradation of $\mathrm{MB}$ is inhibited when the $\mathrm{pH}$ is greater than 11. Because the hydroxyl ions compete with dye molecules in adsorption on the surface of catalyst. ${ }^{23,24}$ Degradation efficiency at presence of $0.1,0.5,0.8,1.0$ and $1.2 \mathrm{~g} / \mathrm{L}$ is obtained 78.6, 88.7, 93.5, 89.1 and 84.2, respectively. As seen, the optimized value of $\mathrm{SnO}_{2}$ nanoparticles is $0.8 \mathrm{~g} / \mathrm{L}$. The active sites and density of particles in the area of illumination are increased with increasing of concentration of catalyst in the photodegradation process. ${ }^{25,26}$ But, at higher catalyst loading of $0.8 \mathrm{~g} / \mathrm{L}$, the activated particles deactivate by agglomeration. Also, the decrease of radiation penetration and increase of radiation scattering occur at higher catalyst loading.

Because the influence of many factors and even their mutual effects, the heterogeneous photocatalysis reaction is complicated process. However, the pseudo-first-order rate equation of Langmuir-Hinshelwood (Eq. 2) is used to determine the apparent rate constant, $k_{a p p}$, of MB photodegradation catalyzed by $\mathrm{SnO}_{2}$ nanoparticles. ${ }^{27}$ The apparent rate constants are obtained at range of $10-50 \mathrm{mg} / \mathrm{L}$ of methylene blue and collected in Table 1 . The regression
Table 1. The apparent rate constants $\left(k_{a p p}, \min ^{-1}\right)$ and regression coefficients $\left(R^{2}\right)$ of methylene blue degradation catalyzed by $\mathrm{SnO}_{2}$ and zaro-valent $\mathrm{Sn}$ nanoparticles calcined at $500{ }^{\circ} \mathrm{C}$

\begin{tabular}{cccccc}
\hline \multirow{2}{*}{$C_{o}, \mathrm{mg} / \mathrm{L}$} & \multicolumn{2}{c}{$\mathrm{SnO}_{2}$ nanoparticles } & & \multicolumn{2}{l}{ Zero-valent $\mathrm{Sn}$ nanoparticles } \\
\cline { 2 - 3 } \cline { 5 - 6 } & $k_{\text {app }}$ & $R^{2}$ & & $k_{\text {app }}$ & $R^{2}$ \\
\hline 10 & $23.3 \times 10^{-3}$ & 0.9553 & & $15.4 \times 10^{-3}$ & 0.9553 \\
20 & $14.7 \times 10^{-3}$ & 0.9824 & & $9.6 \times 10^{-3}$ & 0.9824 \\
30 & $9.0 \times 10^{-3}$ & 0.9914 & & $6.2 \times 10^{-3}$ & 0.9914 \\
40 & $6.4 \times 10^{-3}$ & 0.9678 & & $4.0 \times 10^{-3}$ & 0.9678 \\
50 & $5.8 \times 10^{-3}$ & 0.9812 & & $2.1 \times 10^{-3}$ & 0.9812 \\
\hline
\end{tabular}

coefficients $\left(R^{2}\right)$ of Langmuir-Hinshelwood kinetic model also indicated in Table 1. As seen, the apparent rate constant decrease with increasing of the initial concentration of MB. The decrease of apparent rate constant is due from two reasons: i) increasing the probability of absorption of photons by pollutant molecules and decrease to reach of them to surface of catalyst, ii) increasing of pollutant molecules adsorbed on the surface of catalyst and decrease the active sites to generate of radicals. ${ }^{28,29}$

Photocatalytic activity of prepared $\mathrm{SnO}_{2}$ nanoparticles studied also under sunlight irradiation in optimized conditions. The degradation efficiency of MB was $92.7 \%$ in time 150 min with apparent rate constant of $21.6 \times 10^{-3}$ $\mathrm{min}^{-1}$. As a result, the prepared tin (IV) oxide shows photocatalytic activity under sunlight irradiation as well UVirradation.

The photocatalytic activity of $\mathrm{SnO}_{2}$ nanoparticles investigated in presence of ions of $\mathrm{Ca}^{2+}, \mathrm{Mg}^{2+}, \mathrm{Cl}^{-}, \mathrm{Br}^{-}, \mathrm{I}^{-}, \mathrm{CO}_{3}{ }^{2-}$, $\mathrm{NO}_{3}{ }^{-}, \mathrm{SO}_{4}{ }^{2-}$ and $\mathrm{PO}_{4}{ }^{3-}$ with concentration of $1000 \mathrm{mg} / \mathrm{L}$ as real samples. The effect of each ion on the nanosized $\mathrm{SnO}_{2}$ activity is shown in Fig. 9. However, the photocatalytic activity of $\mathrm{SnO}_{2}$ nanoparticles diminished in a real sample contains cations and anions. This reduction is due to scavenger effect of active radicals by cations and anions. ${ }^{4}$

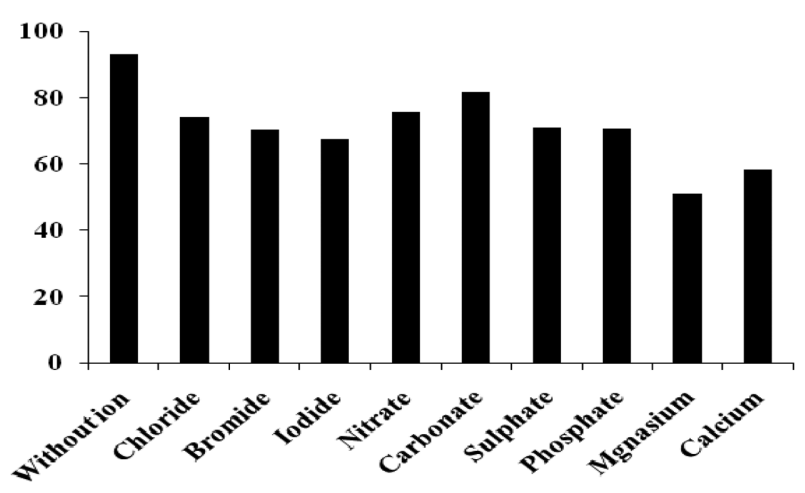

Fig. 9. The effect of several ions on the photocatalytic activity of $\mathrm{SnO}_{2}$ nanoparticles. 
Also, the catalytic activity of tin dioxide nanoparticles is compared to commercially $\mathrm{SnO}_{2}$ with purity of $99.7 \%$. The degradation of $63.4 \%$ of MB is obtained at presence of commercially $\mathrm{SnO}_{2}$ powder. This reduction of degradation efficiency can be due to difference of surface area and band-gap of $\mathrm{SnO}_{2}$ nanoparticles and $\mathrm{SnO}_{2}$ powder. So that, B.E.T (Brunauer-Emmett-Teller) surface area of prepared nanoparticles is obtained $258.3 \mathrm{~m}^{2} / \mathrm{g}$ in comparison of $132.6 \mathrm{~m}^{2} / \mathrm{g}$ of $\mathrm{SnO}_{2}$ powder. The reusability of $\mathrm{SnO}_{2}$ nanoparticles studied in four-cycles. In each cycle, the nanoparticles separated, washed with water and ethanol and dried at $80{ }^{\circ} \mathrm{C}$ and used in next cycles. The $\mathrm{D} \%$ values obtained $97.0,93.7,89.7$ and $82.6 \%$ in order of four-cycles.

\section{Catalytic Activity of Zero-valent Tin Nanoparticles}

The use of zero-valent metal particles such as Sn for decontamination of common soil and water contaminants has been the subject of many studies. ${ }^{30}$ Synthesis of zerovalent tin (ZVT) nanoparticles was achieved by reaction $\mathrm{NaBH}_{4}$ and $\mathrm{SnCl}_{2}$ according to the following equation:

$$
2 \mathrm{Sn}^{2+}+\mathrm{BH}_{4}^{+}+2 \mathrm{H}_{2} \mathrm{O} \rightarrow 2 \mathrm{Sn}(0)+\mathrm{BO}_{2}^{-}+4 \mathrm{H}^{+}+2 \mathrm{H}_{2}(\mathrm{~g})
$$

The bleaching of MB solution studied at presence of 0.8 $\mathrm{g} / \mathrm{L}$ of ZVT nanoparticles and $\mathrm{pH} 11$ like as the optimum conditions in photodegradation reaction. The pseudo firstorder rate constants $\left(k_{\text {app }}\right)$ of MB degradation by ZVT nanoparticles are calculated using Eq. (2) and indicated in Table 1. As seen, the rate constants of MB degradation catalyzed by $\mathrm{SnO}_{2}$ photocatalyst and ZVT nanoparticles are near to each other. The MB degradation is obtained 97.8 and $92.1 \%$ in presence of $\mathrm{SnO}_{2}$ and $\mathrm{Sn}$ nanoparticles, respectively, in duration of $150 \mathrm{~min}$. Thus, reactivity of ZVT nanoparticles in MB degradation process is comparable with photocatalytic activity of $\mathrm{SnO}_{2}$ nanoparticles in photodegradation reaction of dye in spite of different in degradation mechanism. The holes and electrons are produced by $\mathrm{SnO}_{2}$ semiconductor under irradiation and the formation of hydroxyl radicals particularly in basic solution apply as an active species in degradation of MB. ${ }^{31}$ While, zero-valent tin is a strong reducing agent in basic solutions with $E^{o=}=0.91$ and $-0.93 \mathrm{~V}$ for $\mathrm{Sn}$ (II) to $\mathrm{Sn}(0)$ and $\mathrm{Sn}(\mathrm{IV})$ to $\mathrm{Sn}(\mathrm{II})$, respectively (Eq. 4). Furthermore, the most important factor that influences on $k_{a p p}$ is the surface area of the zero-valent metal. ${ }^{32}$

$$
\mathrm{Sn}(\mathrm{OH})_{6} \stackrel{2-}{\stackrel{-0.93}{\longrightarrow}} \mathrm{SnO}_{2} \mathrm{H}^{-} \stackrel{-0.91}{\longrightarrow} \mathrm{Sn}
$$

This means that it can act as an electron donor that due to reduction of MB molecules in basic solution. The methylene blue is a redox indicator with blue color in oxidized form and colorless in reduced form. The reduction of MB is occurred in acidic solutions and this reduction is due to reduction of absorbance at $\lambda_{\max }$ of it in visible region. While, in basic solution $(\mathrm{pH}=11)$ and in presence of $\mathrm{ZVT}$ nanoparticles, the MB molecules degrade and the reduction of absorbance in wavelength ranges of 200-300 and $600-700 \mathrm{~nm}$ is observed in UV-Vis spectra similar to variations of MB absorption spectra in photodegradation reaction. Thus, $\mathrm{Sn}(0)$ nanoparticles as well $\mathrm{SnO}_{2}$ nanoparticles in photodegradation could be due to destruction of a dye pollutant such as MB.

\section{CONCLUSION}

The activity of $\mathrm{SnO}_{2}$ as a photocatalyst is dependent on the calcinations temperature, dosage of it and $\mathrm{pH}$ of samples. Because, the calcinations temperature influence on the band-gap energy and size of particles. The zero-valent tin as reducing agent can be due to degradation of methylene blue in basic solution. In the same conditions of nanoparticles $\left(0.8 \mathrm{~g} / \mathrm{L}\right.$ of catalyst) and sample $\mathrm{pH}$ of 11 , the $\mathrm{SnO}_{2}$ nanoparticles and zero-valent $\mathrm{Sn}$ nanoparticles show similar and attractive activity in degradation of methylene blue as a dye pollutant.

\section{REFERENCES}

1. Robert, D. Catal. Today 2007, 122, 20

2. Jing, L.; Fu, H.; Wang, B.; Wang, D.; Xin, B.; Li, S.; Sun, J. Appl. Catal., B: Environ. 2006, 62, 282.

3. Jing, L.; Wang, D.; Wang, B.; Li, S.; Xin, B.; Fu, H.; Sun, J. J. Mol. Catal., A: Chem. 2006, 244, 193.

4. Augugliaro, V.; Litter, M.; Palmisano, L.; Sori, J. J. Photochem. Photobiol. C 2006, 7127.

5. Liotta, L. F.; Gruttadauria, M.; Di Carlo, G.; Perrini, G.; Librando, V. J. Hazard. Mater. 2009, 162, 588.

6. Pouretedal, H. R.; Norozi, A.; Keshavarz, M. H.; Semnani, A. J. Hazard. Mater. 2009, 162, 674.

7. Pouretedal, H. R.; Eskandari, H.; Keshavarz, M. H.; Semnani, A. Acta Chim. Slov. 2009, 56, 353.

8. Wang, H.; Baek, S.; Lee, J.; Lim, S. Chem. Eng. J. 2009, $146,355$.

9. Dhage, S. R.; Gaikwad, S. P.; Samuel, V.; Ravi, V. Bull. Mater. Sci. 2004, 27, 221.

10. Kandjani, A. E.; Salehpoor, P.; Tabrizi, M. F.; Arefian, N. A.; Vaezi, M. R. Mater. Sci.-Poland 2010, 28, 377.

11. Balan, L.; Schneider, R.; Billaud, D.; Ghanbaj, J. Mater. Lett. 2005, 59, 1080.

12. Lee, K. T.; Jung, Y. S.; Oh, S. M. J. Am. Chem. Soc. 2003, 125, 5652.

13. Bottani, C. E.; Li Bassi, A.; Tanner, B. K.; Stella, A.; Tognini, P.; Cheyssac, P.; Kofman, R. Mater. Sci. Eng., C, 
Biomim. Mater., Sens. Syst. 2001, 15, 41.

14. Depero, L. E.; Bontempi, E.; Sangaletti, L.; Pagliara, S. J. Chem. Phys. 2003, 118, 1400.

15. Krishnakumar, T.; Jayaprakash, R.; Parthibavarman, M.; Phani, A. R.; Singh, V. N.; Mehta, B. R. Mater. Lett. 2009, 63, 896.

16. Anandan, K.; Rajendran, V.; J. Non-Oxide Glasses 2010 , 2,83 .

17. Zhang, M.; An, T.; Hu, X.; Wang, C.; Sheng, G.; Fu, J. Appl. Catal., A 2004, 260, 215.

18. Jiang, L.; Sun, G.; Zhou, Z.; Sun, S.; Wang, Q.; Yan, S.; Li, H.; Tian, J.; Guo, J.; Zhou, B.; Xin, Q. J. Phys. Chem. B 2005, 109, 8774.

19. Zhao, Y.; Zhang, Z.; Dang, H. Mater. Sci. Eng. A 2003, 359, 405.

20. Noh, M.; Kim, Y.; Kim, M. G.; Lee, H.; Kim, H.; Kwon, Y.; Lee, Y.; Cho, J. Chem. Mater. 2005, 17, 3320.

21. Gu, F.; Wang, S. F.; Leu, M. K.; Qi, Y. X.; Zhou, G. J.; $\mathrm{Xu}, \mathrm{D}$; Yuan, D. R. Inorg. Chem. Commun. 2003, 6, 882.

22. Rodriguez-Santiago, V.; Fedkin, M. V.; Wesolowski, D. J.; Rosenqvist, J.; Lvov, S. N. Langmuir 2009, 25, 8101.
23. Pouretedal, H. R.; Hosseini, M. Acta Chim. Slov. 2010, 57, 415.

24. Pouretedal, H.R.; Kadkhodaie, A. Chin. J. Catal. 2010, $31,1328$.

25. Nezamzadeh-Ejhieh, A.; Hushmandrad, S. Appl. Catal., A 2010, 388, 149.

26. Nezamzadeh-Ejhieh, A.; Salimi, Z. Appl. Catal., A 2010, $390,110$.

27. Wang, K.; Zhang, J.; Lou, L.; Yang, S.; Chen, Y. J. Photochem. Photobiol. A 2004, 165, 201.

28. Pouretedal, H. R.; Keshavarz, M. H. J. Alloys Comp. 2010, $501,130$.

29. Kudo, A.; Niishiro, R.; Iwase, A.; Kato, H. Chem. Phys. 2007, 339, 104.

30. Lin, C. J.; Liou, Y. H.; Lo, S. L. Chemosphere 2009, 74, 314.

31. Hoffmann, M. R.; Martin, S. T.; Choi, W.; Bahnemannt, D. W. Chem. Rev. 1995, 95, 69.

32. Satapanajaru, T.; Chompuchan, C.; Suntornchot, P.; Pengthamkeerati, P. Desalination 2011, 266, 218. 